\title{
0 caso Transtorno do Déficit de Atenção e Hiperatividade (TDAH) e a medicalização da educação: uma analise a partir do relato de pais e professores
}

\author{
Murilo Galvão Amancio Cruz(a) \\ Mary Yoko Okamoto(b) \\ Daniele de Andrade Ferrazza(c)
}

Cruz MGA, Okamoto MY, Ferrazza DA. Attention Deficit/Hyperactivity Disorder case (ADHD) and the medicalization of education: an analysis from parents and teachers' reports. Interface (Botucatu). 2016; 20(58):703-14.

Difficult behaviors in childhood are the center of frequent discussions in the medical and educational areas in the last years. Two interrelated phenomena stand out in this debate: the medicalization and pathologization of childhood. Medicine and psychiatry are known as producers of these processes creating and recreating diagnostic categories to justify innumerable problems in the complex relationships in the school environment. From this perspective, we intend to bring the narratives of parents and teachers from a public school in the state of São Paulo about students, aged between seven and 11 years old, diagnosed with Attention Deficit/Hyperactivity Disorder (ADHD) that link with discussions about the medicalization process in the present society. It is considered that children who have shown difficulties in learning or behaving are categorized as biological ahistorical bodies lacking social and affective life.

Keywords: ADHD. Medicalization. Childhood. Parents. Teachers.
As dificuldades de comportamento na infância têm sido alvo de inúmeras discussões na área médica e educacional, sobretudo nos últimos anos. Com isto, dois fenômenos inter-relacionados se sobressaem: a medicalização e a patologização da infância. A medicina e a psiquiatria são saberes produtores destes processos ao criarem e recriarem categorias diagnósticas que justifiquem inúmeros problemas da rede de relações complexas que caracterizam o ambiente escolar. Nesta perspectiva, pretendemos trazer o relato de pais e professores de uma escola pública do interior de São Paulo sobre alunos, com idade entre sete e 11 anos, diagnosticados com Transtorno do Déficit de Atenção e Hiperatividade (TDAH) e relacioná-lo com as discussões acerca do processo de medicalização na atualidade. Considera-se que as crianças que apresentam dificuldades de aprendizagem ou comportamento são categorizadas como um corpo biológico a-histórico desprovido de vida social e afetiva.

Palavras-chave: TDAH. Medicalização. Infância. Pais. Professores.

\footnotetext{
(a) Pós-graduando, Departamento de Políticas e Instituições de Saúde, Instituto de Medicina Social, Universidade do Estado do Rio de Janeiro. Rua São Francisco Xavier, 524, Pavilhão João Lyra Filho, $7^{\circ}$ andar, Maracanã. Rio de Janeiro, RJ, Brasil. 20550-013. murilogac@gmail.com (b) Departamento de Psicologia Clínica, Faculdade de Ciências e Letras de Assis, Universidade Estadual Paulista "Júlio de Mesquita Filho". Assis, SP, Brasil. mary.ok@assis.unesp.br (c) Departamento de Psicologia, Universidade Estadual de Maringá. Maringá, PR, Brasil. daferrazza@uem.br
} 


\section{Introdução}

Queixas escolares e comportamentais têm aumentado significativamente o número de diagnósticos psiquiátricos na infância. Esse aumento está relacionado ao surgimento de inúmeras estratégias e discursos que sustentam práticas medicalizantes na educação e a consequente patologização da infância - processos caracterizados pelas veiculações midiáticas de discursos sobre as bases neurobiológicas de mal-estares psíquicos, cuja terapêutica proposta seria exclusivamente a prescrição de pílulas que prometem restabelecer desequilíbrios neuroquímicos. Tais discursos instalam-se no imaginário público e influenciam as concepções da população com intuito de incluir famílias e professores no dispositivo de medicalização ${ }^{1}$. A extensa informação propagada pelos meios de comunicação, que disponibilizam dados sobre as características dos diagnósticos psis, bem como testes para facilitar a identificação de supostos transtornos, têm promovido o uso comum de elementos dos discursos neurocientíficos e o estabelecimento de práticas de autocontrole e vigilância para que qualquer pessoa possa reconhecer os outros ou a si como portadores de uma doença mental ${ }^{2}$.

Dessa forma, é comum na contemporaneidade o encaminhamento de crianças para clínicas médicas a fim de sanar os supostos problemas de comportamento e/ou aprendizagem. Na busca pelo filho e aluno ideais, pais e professores procuram, nos saberes médico-neuropsiquiátricos, a solução para suas dificuldades. A escola torna-se ambiente de propagação do processo de medicalização, interpenetrada pela instituição médica, e um lugar privilegiado de seleção das crianças passíveis de serem medicalizadas - mas será que caberia aos profissionais da saúde lidar com um campo tão profuso como o da educação? Segundo Vorcaro ${ }^{3}$, a desvalorização do conhecimento dos pais e o deslocamento de suas posições para o saber específico da medicina se intensificam a partir da ampliação dos quadros clínicos, gerada pelas edições do Diagnostic and Statistical Manual of Mental Disorders (DSM) já que, supostamente, o saber parental não poderia cuidar das dificuldades e déficits do filho, o que os leva a buscar o saber científico com absoluta confiança.

Com efeito, a medicina, a psiquiatria e a psicologia são saberes que estão intrinsecamente associados ao poder de medicalizar, psiquiatrizar e patologizar, uma vez que diagnosticam fenômenos humanos em busca de um tratamento que deve normalizar o sujeito desviante, ou seja, aquele que se afasta do denominado ponto médio padrão. O processo de medicalização pode ser compreendido como a apropriação pelo saber médico de questões políticas, econômicas, socioculturais, e existenciais que, portanto, não pertenciam ao pleno domínio da medicina. Foucault $t^{1,4,5}$ e Illich ${ }^{6}$ foram dois grandes intelectuais que iniciaram discussões contemporâneas acerca deste complexo fenômeno, imerso em uma rede múltipla de poderes.

Sobretudo a partir da década de 1980, com a publicação da terceira edição do DSM, a psiquiatria biológica ganhou força e passou a interpretar os chamados transtornos mentais a partir de uma explicação causal entre a neuroquímica do cérebro e o comportamento apresentado. De fato, esta psiquiatria tenta se aproximar da medicina somática, e tem como principal característica estabelecer a etiologia, terapia e diagnóstico das doenças mentais, utilizando um correlato biológico que tem uma compreensão fisicalista do ser humano e une biologia, genética, neurociência e classificação psiquiátrica. Destarte, o sofrimento psíquico passa da ordem narrativa de uma história singular para a ordem cerebral, reduzindo-se, portanto, ao cérebro. Assim, a medicina cumpre seu papel higienista em um movimento que (1) parte da ciência médica para, (2) o desejo de gerir a população, (3) enquanto uma instância normativa, (4) que é componente do biopoder, e, finalmente, (5) produz uma multiplicação das doenças ${ }^{7}$.

Os processos singulares são capturados pelo saber médico na medida em que o comportamento divergente é considerado exclusivamente disfunção orgânica do indivíduo, o que justificaria suas dificuldades sociais. Desta forma, os processos de medicalização da vida tendem a transformar dificuldades e divergências em problemas de origem e solução no campo médico ${ }^{8}$. Um diagnóstico exemplo destas problematizações que vem sendo bastante discutido é o TDAH - Transtorno do Déficit de Atenção e Hiperatividade. Descrito pela grande maioria das pesquisas atuais como um dos transtornos neuropsiquiátricos mais comuns à infância, com hipóteses de que afetaria cerca de $7 \%$ da população mundial ${ }^{9}$, teria como tratamento, muitas vezes único e exclusivo, a prescrição de 
psicofármacos. Suas características, segundo o próprio DSM, seriam marcadas pela tríade desatenção, hiperatividade e/ou impulsividade, aspectos que supostamente assumiriam formas combinadas ou separadas. Todavia, a popularização do termo "criança hiperativa" passou a preocupar muitos estudiosos que questionam suas bases biológicas e seu tratamento medicamentoso e denunciam a banalização deste diagnóstico para a infância contemporânea. Atentas a esta crítica, Caliman e Domitrovik ${ }^{10}$ afirmam:

O TDAH poderia ser analisado como uma desordem sem fronteiras [...] - um diagnóstico psiquiátrico que parece não possuir limites internos nem externos. Desde sua constituição, na década de 1970, presenciamos um processo crescente de expansão da categoria. Antes considerado uma desordem transitória e infantil, que raramente alcançava a adolescência, o TDAH é agora descrito como um transtorno psiquiátrico que pode perdurar por toda a vida do indivíduo - um quadro incurável. Uma vez visto como a causa para o baixo desempenho escolar, o transtorno passou a ser uma explicação biológica "plausível" para as dificuldades da vida, sejam elas acadêmicas, profissionais, emocionais, familiares e, mesmo, sexuais [...]. (p. 883-4)

Nessa perspectiva, o presente trabalho procura problematizar o fenômeno da psicopatologização da vida que perpassa a infância na atualidade e pretende relacionar o relato de pais e professores sobre crianças diagnosticadas com TDAH à discussão em torno do processo de medicalização da educação.

\section{O processo de medicalização da educação e a patologização da infância}

Transportar a discussão sobre a medicalização para o campo da educação é caminhar por espaços sinuosos, nos quais habita uma rede de instituições que se interpenetram, da qual destacamos a educação, a família e a medicina. A maioria das crianças, sobretudo entre sete e 14 anos, passa a maior parte do tempo nas escolas, desta forma, é inevitável que professores presenciem comportamentos, gestos e atitudes consideradas inadequadas aos padrões, além das dificuldades de aprendizado difíceis de serem enfrentadas.

É certo que a escola, instituição disciplinar do fim do século XVIII, já tinha como mecanismo o olhar vigilante do professor sobre os alunos hierarquizados pelo saber. Segundo Foucault ${ }^{11}$, a classe a partir do fim do século XVIII "se compõe por elementos individuais que vem se colocar uns ao lado dos outros sob os olhares do mestre" (p. 125). Todavia, na contemporaneidade há um novo mecanismo que instiga a vigilância. É que ao se deparar com comportamentos indesejados e que fogem do esperado, os professores buscam respostas imediatas para solucionar problemas institucionais marcados pelas principais características das instituições disciplinares em crise ${ }^{12}$, que investem no processo de medicalização a fim de expandir e produzir saberes que pretendem contornar as situações consideradas problemáticas. Dessa forma, a medicina se apropria do espaço escolar e o professor passa a ter um olhar mais vigilante sobre as crianças buscando classificações para suas diferenças individuais. Para Machado 13: "Nasce a crença de que as faltas são de ordem individual e que é possível preencher o que falta. Como se a falta de disciplina, atenção, esforço e concentração dos alunos e a falta de dedicação dos pais acontecessem por uma certa falta de vontade de mudar e lutar" (p. 120).

Não só a medicina, mas a psiquiatria e a psicologia tiveram um papel crucial na história desta aproximação - um tanto perigosa - entre saúde e educação. Perigosa a partir do momento em que seu objetivo era simplesmente a profilaxia dos desviantes e a consequente cura do "mau comportamento", que se expressava, sobretudo, em crianças pobres, negras e com uma estrutura familiar dissidente da norma, ou seja, crianças que refletiam aquilo que a psicologia e a psiquiatria foram chamadas a organizar: o caótico que é, em suma, herança do higienismo no Brasil. O movimento higienista tinha a tendência, no século XIX, a associar questões sociais aos discursos e práticas psicológicas e psiquiátricas, apoiando-se na hipótese da causalidade biológica que justificava a intervenção médica em toda sociedade ${ }^{14}$. Como aponta Patto ${ }^{15}$, desde o seu surgimento enquanto ciência na modernidade, a psicologia serviu para apontar, avaliar, separar e excluir a criança considerada idiota. 
Já na segunda metade do século XVIII, a observação sistemática e o registro de condutas possibilitou a constituição de um saber sobre o homem que, conforme Foucault ${ }^{16}$, culminaria no nascimento da psicologia, da pedagogia, da psiquiatria que constituiriam discursos sobre uma verdade imutável, universal, neutra e a-histórica do ser humano. As ciências psis carregavam em suas concepções e práticas a herança das ciências de ajustar comportamentos e disciplinar os corpos, baseada em uma definição conservadora de normalidade que considerava normal o comportamento socialmente aceito e que valorizava a ordem quantitativa para classificação do normal e do patológico ${ }^{17}$.

No contexto brasileiro de princípios do século XX, a medicina, influenciada pelas concepções higienistas, ao se inserir nos contextos educacionais, carregaria predominantemente concepções patologizantes que iriam mascarar os problemas relacionados ao fracasso escolar. Com a ênfase nas técnicas psicométricas em âmbitos escolares, tornou-se plausível encontrar respostas individuais para problemas sociais.

$\mathrm{Na}$ atualidade, com a predominância do discurso biologicista, a medicina e a psiquiatria não dispensam o olhar individualizante e falam de transtornos que decorrem supostamente da neuroquímica cerebral. O TDAH, como conhecemos hoje, já foi a criança com suposto defeito no controle moral, passou pela criança portadora de uma deficiência mental leve que carregava sintomas de hiperatividade, e inclusive aquela que apresentava um cérebro moderadamente disfuncional, posteriormente chamada de criança com Déficit de Atenção ${ }^{18}$.

Hoje, crianças e adolescentes têm sido rotulados com TDAH e medicados com psicofármacos, principal tratamento determinado para o fracasso escolar e dificuldade de aprendizagem.

\section{Metodologia}

Os procedimentos da presente pesquisa foram aprovados pelo Comitê de Ética da Faculdade de Ciências e Letras de Assis/Unesp.

Os impactos do diagnóstico de TDAH e do tratamento determinado às crianças foram estudados por meio de entrevistas realizadas com pais e/ou responsáveis e professores de quatro alunos indicados pela coordenação de uma escola municipal do interior paulista que possuíam o diagnóstico de TDAH. Iniciamos a coleta de dados por meio da análise de relatórios disponibilizados pela escola sobre as crianças diagnosticadas. Posteriormente, foram realizadas entrevistas semidirigidas com questionamentos básicos a respeito do TDAH e a relação da determinação diagnóstica com a vida escolar e o impacto do diagnóstico e do tratamento na vida da criança. Foram entrevistados quatro professores, três mães e uma avó. Todos os entrevistados tinham vinculação com as crianças diagnosticadas.

Para a análise das entrevistas, foram usados os discursos por meio da criação de oito categorias ${ }^{19}$ : quatro abordando os principais aspectos sugeridos pelas mães e avó e quatro categorias relacionadas aos discursos dos professores. Em relação às mães e avó, podemos destacar quatro categorias de análise: a) diagnóstico; b) mudanças após o tratamento; c) causas relacionadas ao TDAH; d) preocupação com o futuro. Já na visão dos professores, destacamos: a) comportamento na escola antes e após o tratamento; b) causas relacionadas ao TDAH; c) critérios e ações; d) posição na sala de aula em relação ao aluno diagnosticado.

\section{Resultados e discussões}

Antes de apresentarmos as análises das categorias, iremos descrever, de maneira geral, as principais características das quatro crianças. Todos os nomes são fictícios.

Pedro tem sete anos de idade, está matriculado no $2^{\circ}$ ano do Ensino Fundamental (E.F.) e mora com a avó. Segundo ela, um médico "achou" (sic) que ele tinha um "problema" (sic) de hiperatividade e receitou um remédio do qual não lembra o nome. Segundo informações de um dos primeiros relatórios da pré-escola, a criança era quieta e conversava pouco. Já no último relatório da pré-escola, escrito no 
ano anterior ao ingresso no EF, Pedro apresentava dificuldades em se concentrar e cooperar com os colegas. No $1^{\circ}$ ano, segundo a coordenadora pedagógica, a criança era bastante inquieta e hiperativa. Segundo a sua atual professora, ele é um aluno muito inteligente, mas não permanece quieto em sala de aula. Para a avó, ele presta atenção por pouco tempo nas coisas e é muito agitado até para dormir. Por conta disto, foi receitado outro remédio para ele "se acalmar e dormir à noite" (sic), mas a avó não vê melhora.

Carlos está no $3^{\circ}$ ano do E.F. e tem oito anos. Mora com os pais e possui dois diagnósticos médicos em sua ficha escolar, com um mês de diferença entre eles. No primeiro, um neuropediatra determinou o diagnóstico de TDAH, da forma combinada: hiperatividade e desatenção com prescrição de Ritalin@ e ajuda pedagógica individual. No mês seguinte, o mesmo médico diagnosticou transtorno de aprendizagem por imaturidade cerebral, justificando que "essas crianças não respondem ao psicoestimulante e que há necessidade de ajuda pedagógica individual". A professora relata que Carlos é uma criança agitada, movimenta-se o tempo todo e não presta atenção por muito tempo.

Samuel está no $4^{\circ}$ ano do E.F., tem 11 anos e mora com os pais. Já passou por vários especialistas, com os seguintes diagnósticos: transtorno de aprendizagem, dislexia e déficit de atenção. Segundo relato da professora, ele está em "outro mundo e basta passar um bichinho em sua frente para sua atenção voltar totalmente aquilo" (sic). A mãe procurou ajuda médica devido a duas convulsões que ele teve na escola e, a partir de então, começaram as buscas por um diagnóstico. De acordo com a mãe, que relata "já estar cansada de ir atrás disso tudo e nada resolver" (sic), a família procurou ajuda profissional após a solicitação da professora do $1^{\circ}$ ano. Conforme relatado pela mãe e professora, a criança passou a tomar Ritalin@ para ir à escola e Amytrilpara se acalmar e dormir à noite. Segundo a mãe, ele usou a Ritalin@ por dois meses, mas como não houve efeito, ela voltou ao médico para retirar a medicação. Para ela, a criança apresenta maiores dificuldades na escola.

Henrique mora com os pais e está no $5^{\circ}$ ano do E.F., tem dez anos e diagnóstico de déficit de atenção. Segundo a atual professora, ele tem muita dificuldade de aprendizagem e é desorganizado, embora seja muito esforçado, fato atribuído à família que é, segundo a professora, bastante presente e apoia o filho. Foi medicado com Ritalin@, o que a professora avaliou como negativo. A mãe relata que na escola ele é de um jeito e em casa é totalmente diferente; os sintomas só apareceram a partir do $3^{\circ}$ ano da escola. Segundo ela, Henrique é agressivo e Ihe falta concentração, mas considera que ele está bastante melhor agora.

\section{1) Mães e avó}

a) Diagnóstico:

A avó de Pedro buscou ajuda médica assim que as queixas escolares se iniciaram. Foi prescrito um tratamento medicamentoso e indicado um psicólogo, no entanto a avó mostra-se confusa e não sabe afirmar ao certo qual é o diagnóstico e como ele se deu, embora a consideração médica tenha como consequência a utilização de dois medicamentos.

A mãe de Carlos também procurou auxílio médico após um contato da professora que solicitou o encaminhamento da criança que "não parava quieta na carteira" (sic). Um neuropediatra diagnosticou imaturidade cerebral e, segundo ele, a falta de concentração seria consequência desta condição.

O diagnóstico de Samuel adveio de duas convulsões na escola. De acordo com a mãe, ela o levou ao médico que iniciou uma pesquisa com a criança, diagnosticada em um primeiro momento com dislexia e, posteriormente, com TDAH. Este permanece entre a condição de dislexia e déficit de atenção, já "que é um TDAH com as características de um disléxico então ficou meio entre as duas coisas..." (sic).

A mãe de Henrique procurou auxílio médico por ele ser considerado muito agitado na escola, o que levou à determinação do diagnóstico de déficit de atenção.

Como vimos, os quatro casos analisados apresentam ao menos duas questões em comum.

Primeiramente, todos os responsáveis procuraram o auxílio médico a partir de demandas escolares, não médicas, com exceção da mãe de Samuel, que procura atendimento após as convulsões vividas pelo filho na escola. No entanto, é interessante destacar que, naquele caso, apesar da condição específica, 
seu diagnóstico final não está relacionado à condição vivida, mas aos problemas relacionados às dificuldades de leitura e atenção na instituição de ensino. Em segundo lugar, destaca-se que todas as crianças saíram da consulta médica com um diagnóstico psiquiátrico, ainda que o responsável apresente dúvidas sobre a rotulação diagnóstica. Além disso, todas as crianças foram submetidas a um tratamento medicamentoso.

Neste contexto, Moysés ${ }^{20}$ alerta para o fato de que, ao se desistir de um aluno, seja pelo motivo que for - social, econômico, médico, político - com afirmações de que o não aprendizado ocorre devido a uma incapacidade individual, já se cria um futuro estigmatizado para aquela criança. Quando o aluno deixa de resistir e de se rebelar e se submete aos discursos de normalização e disciplinamento, tão presentes nos espaços escolares, poderá ser refém de uma incapacidade que não tem, mas introjetou, "preso em uma doença que não existe. Está confinado em uma instituição invisível, sem paredes, virtual" 20 (p. 21). Já que aquelas crianças foram expropriadas de sua normalidade por meio da determinação diagnóstica ${ }^{21}$, acabam por incorporar a incapacidade que insistem em lembrar que têm: "Não sabem ler!", "Não param na carteira!".

\section{b) Mudanças após o tratamento:}

O tratamento determinado nos casos foi exclusivamente medicamentoso, salvo em um dos casos em que houve a indicação simultânea de atendimento psicológico.

Para Pedro, foram indicadas duas medicações: uma para sua concentração durante o dia e uma para "acalmar e descansar a mente durante a noite" (sic). Para a avó, no entanto, os medicamentos não surtiram efeito "porque eu dou tudo certinho, e ele continua assim" (sic). Já o tratamento psicológico, considera bastante positivo, uma vez que o auxiliou e ocasionou mudanças em seu comportamento.

No caso de Carlos, também houve indicação de dois medicamentos com o mesmo propósito: estimular durante o dia e acalmar durante a noite. No entanto, a professora procurou por sua mãe e disse não ter visto nenhum efeito positivo com a medicação. Diante disso, a mãe optou por retirar a medicação e procurar novamente o profissional médico que afirmou que "só o tempo ia ajudar ele" (sic), já que o problema era devido à imaturidade cerebral. A mãe é enfática ao dizer: "não, não houve mudança alguma após o diagnóstico" (sic).

Samuel saiu da consulta médica com uma receita de Ritalin@, entretanto, conforme relatos, a medicação não ocasionou mudança alguma, o que foi justificado da seguinte forma: "a médica falou que não resolveu pelo cérebro ser imaturo. E a Ritalin@ não resolve se o cérebro não estiver maduro" (sic).

Já Henrique saiu com a determinação de um tratamento psicofarmacológico e, conforme a mãe, o uso da medicação trouxe inúmeros pontos positivos, embora com o tempo a medicação tenha sido retirada, com a justificativa de que a criança entraria na $5^{\text {a }}$ série e poderia ser liberada deste tratamento.

Despreocupada com efeitos colaterais e com os riscos de dependência química e psicológica, a psiquiatria atual parece determinar o uso de psicofármacos para todas as crianças consideradas problema ${ }^{2,22}$. No entanto, com exceção da mãe de Henrique, os responsáveis não viram quaisquer mudanças positivas no comportamento da criança após o uso contínuo da medicação. Percebe-se que o consumo medicamentoso tornou-se uma espécie de válvula de escape diante das demandas escolares. Contudo, frente à ineficácia do tratamento psicofarmacológico, a maioria dos responsáveis retirou a medicação no período de dois a seis meses, após constatarem que não obtiveram o efeito esperado. Destaca-se que a argumentação para a retirada da medicação permeou o discurso de que o problema era de ordem individual e biológica: imaturidade cerebral. O tratamento psicológico foi considerado positivo no único caso em que foi indicado.

\section{c) Causas relacionadas ao TDAH:}

As causas atribuídas às dificuldades apresentadas pelas crianças são variadas e, de modo geral, os responsáveis se mostram confusos em relação à questão. A avó de Pedro pontua a rejeição dos pais como um fator emocional - psicológico - que culminaria no suposto problema da criança, como a 
causa de seu hipotético transtorno: "A rejeição eu acho que se torna algum problema pra criança" (sic). O lado genético também é destacado, sobretudo pela mãe de Carlos: "Será que não é genético? De alguém que ele... (sic). [...] Eu, por exemplo, eu não faço uma coisa só ao mesmo tempo". (sic). Para a mãe de Samuel, o TDAH é um distúrbio da própria criança que se encontra no âmbito fisiológico: "Acho que é da própria criança, né? Não tem como a gente saber o que passa no cérebro, né?" (sic). Por fim, a mãe de Henrique não atribui causa alguma e, apesar de afirmar não saber, localiza no âmbito do comportamento adquirido.

Embora todos ainda apresentem dúvidas e incertezas, é perceptível nas colocações das entrevistadas a ênfase pelas concepções causais do TDAH relacionadas aos problemas individuais, sejam de ordem psicológica, genética, cerebral e/ou comportamental. Conforme Patto ${ }^{15}$, no atual panorama psicologizante, se enfatizam processos de individualização, nos quais se desconsideram as problemáticas que envolvem as relações institucionais e o problema passa, então, a ser exclusivamente do aluno que não aprende e do filho que não se comporta adequadamente.

\section{d) Preocupação com o futuro:}

Uma questão patente nas entrevistas é a preocupação com o futuro das crianças. A avó de Pedro teme o que possa acontecer no futuro: "eu estou fazendo tudo, tudo que tiver no meu alcance pra ajudar ele, pois quero que ele seja uma criança, assim, normal, como as outras crianças que acompanham... Quero que amanhã ele tenha um futuro..." (sic). A mãe de Carlos também destaca sua preocupação com o futuro, "eu quero fazer hoje o melhor pra depois, né..." (sic). Salienta, ainda, o desejo de encontrar uma solução: "eu paguei uma consulta de $\mathrm{R} \$ 400,00$, comprei remédio, se fosse isso... se a médica falasse pra mim: 'é isso que vai resolver o caso dele', eu tinha continuado. Fazia de tudo" (sic). Para a mãe de Samuel, o futuro da criança é relativo: se a família der apoio e incentivo, pode ser melhor: "tem que ser positivo, né? Tem que ser sempre... Não pode ser negativo pra falar que ele não vai conseguir que senão não vai conseguir mesmo" (sic). Já a mãe de Henrique declara que não tomar providências hoje pode causar problemas futuros como, por exemplo, "andar com má companhia, essas coisas [...]" (sic).

Fica evidente quanto o imaginário das mães/responsáveis é amplo no que diz respeito à forma como um diagnóstico psiquiátrico pode repercutir no futuro da criança, além de ser revelada a esperança de que o tratamento médico e medicamentoso possa transformar e proporcionar uma condição de vida melhor para a criança. Com efeito, no imaginário social, o diagnóstico e tratamento médico se misturam com questões que não são de ordem exclusivamente médica e se aproximam de aspectos do âmbito legal e criminal22.

\section{Professores}

\section{a) Comportamento:}

Para os professores, o comportamento da criança é fundamental para a determinação do diagnóstico e tratamento do TDAH. Pedro, segundo sua professora, é constantemente agitado. "É inteligente, porém, totalmente disperso" (sic). A professora de Carlos destaca a dificuldade do aluno em permanecer sentado: "Chega a doer nele, chega a doer, ser físico, causa angústia nele ficar sentado por mais de dois, três minutos. Ele precisa levantar. É uma necessidade dele. Do movimento constante..." (sic). Para a professora de Samuel, a criança "só está ali de corpo presente [...] ela fica alheia a tudo que está à sua volta" (sic). Já a de Henrique declara que a dificuldade de comportamento da criança é, sobretudo, de atenção, que acaba dificultando sua aprendizagem.

Em relação às mudanças de comportamento percebidas após o diagnóstico, os resultados demonstram que todas as professoras veem a conscientização e a determinação do diagnóstico como positivas, pois se desejava uma explicação médica que só advinha, segundo elas, após o apoio da família.

No que concerne ao tratamento, há diferentes opiniões. Em relação às mudanças propiciadas pelo uso de medicação, uma das professoras alegou não ter notado diferenças no comportamento do aluno, e duas consideraram seu uso negativo por acreditarem que o psicofármaco produzia efeitos 
inadequados e indesejáveis: "porque ter uma criança dopada também aos oito anos, nove anos de idade não resolve nenhum problema, né?" (sic). (Professora de Henrique). Chama a atenção o fato de que a melhora da condição da criança considerada problema em sala de aula está associada sobretudo à participação em atividades, tais como estímulo pedagógico e natação, esta vista como um exercício que "acalma" os alunos.

Dessa forma, percebe-se que, apesar de as professoras julgarem positiva a determinação do diagnóstico TDAH, a solução tida como essencial pela medicina, sempre pautada na prescrição de psicofármacos ${ }^{2}$, não é considerada relevante pelo corpo docente para as mudanças comportamentais das crianças em sala de aula.

\section{b) Causas relacionadas ao TDAH:}

Todas as professoras apontam a questão familiar como causa da dificuldade apresentada pela criança. Para algumas, existem questões genéticas e psicológicas (como fatores relacionados à rejeição e ao trauma). Uma das professoras considera que a família é crucial e a genética influencia; para outra, a genética é a principal causa e a família exerce alguma influência. Este fato coloca em questão a importância dada ao biológico a fim de uma comprovação científica localizada no sujeito - uma doença genética. Apenas uma professora apontou a questão socioeconômica: "A gente não conhece as crianças fora daqui. Então, a maior parte tem problemas sérios familiares, como rejeição... A gente percebe muita pobreza" (sic). (Professora do Pedro). "Seria um transtorno genético ou é... como colocaria? Em algum momento da vida... passado por um trauma ou algum outro tipo de transtorno teria gerado esse problema a nível psicológico" (sic). (Professora do Carlos). "Então pode ser problema familiar e pode ser também alguma genética, algum problema de saúde mesmo, mental" (sic). (Professora do Samuel). "Eu acho que a causa é biológica, apesar de que eu penso que a família poderia não controlar, mas acho que a família é importante desde que saiba e aja a favor disso" (sic). (Professora do Henrique).

\section{c) Critérios e ações:}

Ao se depararem com comportamentos que chamam a atenção, as professoras, de modo geral, tomam algumas atitudes.

A de Pedro elabora relatórios, indica os "alunos problemáticos" à coordenação e tenta recomendar alguma atividade, como equoterapia, natação ou estímulo pedagógico, mas ressalta que não encaminha a criança por estar atrapalhando, pura e simplesmente: "Se ela atrapalha, mas faz, então não tem motivo pra mandar..." (sic). A professora de Carlos também dirige os casos à coordenação com o objetivo de fazer com que a criança obtenha um laudo, "porque assim de repente essa criança tem algum outro tipo de transtorno" (sic). Seu critério é a observação em sala de aula. A professora de Samuel também faz o encaminhamento e a elaboração de relatórios, mas seu método é a sondagem. Ela afirma: "eu vou ditando, a criança vai escrevendo, e você vai vendo o nível que a criança está, se ela está em um nível pela idade dela, dependendo do nível que ela está, alguma coisa está errada" (sic). Então perguntamos a ela: "e pela sondagem você observa também a dificuldade de comportamento, por exemplo, a hiperatividade e desatenção?" (sic). Ao que ela responde: "sim, por ali eu observo tudo" (sic). A professora de Henrique, quando desconfia de alguma coisa, a partir de agitações fora do comum, falta de atenção ou dificuldade de aprendizagem, envia "para uma pessoa responsável, conversa com a família e indica tratamento psicológico, um atendimento avaliativo mesmo, pra que sejam tomadas as medidas necessárias" (sic).

Percebe-se que, como as professoras relacionam a causa do problema a questões de ordem individual, familiar, biológica, orgânica ou cerebral, a forma como determinam os critérios para identificar o aluno que apresenta dificuldades ou problemas de comportamento sempre está direcionada aos gestos, atitudes, modos de ser, falar e se comportar da criança, e nada tem a ver com as relações institucionais ou com o sistema educacional ${ }^{22}$.

d) Posição na sala de aula em relação ao aluno diagnosticado:

Apesar do discurso preponderante de que os alunos não se sentem diferentes em relação aos outros, quando indagados a respeito do modo como lidam com essas crianças em sala de aula, todos 
afirmam ter posições diferenciadas: colocar a carteira próxima ao professor, chamar atenção, passar atividades mais lúdicas, entre outras.

"A minha posição é igual com todas as crianças. Eu não faço distinção nenhuma... A única coisa é que ele se sobressai, então, você tem que chamar mais atenção... E normalmente, ele senta na frente" (sic) (Professora de Pedro). "Ah, ele senta na frente, próximo a mim. Eu procuro tratá-lo como os outros, sem distinção nenhuma, não tenho essa questão de 'ele é laudado, vou tratar diferente' não" (sic) (Professora de Carlos). Para a professora de Samuel, a questão é mais complexa. Ela afirma: "Eu até inclusive separei um pouquinho a sala. Eu tento não deixar muito na cara que eles estão assim divididos. Porque os que eu sinto que necessitam de uma atenção especial na verdade são quatro alunos da minha sala. Então, o que eu fiz: os coloquei bem pertinho um do outro e aí os outros que achamos ter uma facilidade maior deixamos um pouco mais livres. Assim, não há uma separação nenhuma entre eles. Só a carteira deles que fica mais perto, né? Trago atividades diferenciadas pra eles... dentro do que estudamos em sala, eles aprendem de uma maneira mais lúdica. De vez em quando ainda dá pra encaixar eles em alguma atividade que eu faço com os demais alunos" (sic) (Professora do Samuel). Neste caso, fica clara a repercussão e o efeito que um diagnóstico pode produzir em sala de aula. A professora nega a diferença, mas age de maneira absolutamente diferente. Para a de Henrique, a localização em sala de aula também é destaque: "ele senta sempre em frente à minha mesa" (sic).

Em todas as situações relatadas, pode-se perceber como as docentes apresentam comportamentos que, ainda que acusem o contrário e tentem mostrar comprometimento com os alunos diagnosticados, perpassam pela diferenciação e classificação binária entre grupos de alunos considerados adequados e bons e, do outro lado, inadequados e ruins - fato evidenciado pela forma de colocar o aluno com dificuldades próximo à mesa do professor ou separar na sala de aula os que não apresentam grandes dificuldades de aprendizagem.

\section{Considerações finais}

O saber médico-psiquiátrico da atualidade parece não se atentar à criança enquanto ser em processo de subjetivação que vive, deseja e expressa seus conflitos existenciais de maneira singular, conforme as especificidades sociais, culturais, políticas que também influenciarão na constituição da história de vida de cada indivíduo ${ }^{22}$. Destarte, a tarefa da medicina se reduz a categorizar comportamentos, gestos e atitudes consideradas inadequadas e determinar diagnósticos e tratamentos, em sua maioria, medicamentosos, sem restrições. Transformam-se, então, comportamentos infantis que divergem do esperado em doenças, sustentando um processo de patologização que possui um aval científico e médico supostamente inquestionável.

Nota-se que, apesar de os relatos de pais e professoras a respeito da ineficácia da medicação, a busca por uma solução terapêutica rápida é preponderante diante das dificuldades apresentadas ou notadas nas crianças. No âmbito escolar, o uso da medicação é um processo cada vez mais presente, independente do fato apontado nesta pesquisa a respeito de os professores não notarem melhoras no comportamento da criança medicada. Tal posicionamento corrobora a literatura sobre o tema, a qual aponta uma popularização do saber psiquiátrico, que exclui o saber parental constitutivo do laço social e afetivo, para reduzi-lo apenas ao saber médico. De fato, o saber parental e até mesmo popular se enfraquece diante de uma afirmação médica a respeito do comportamento infantil, já que ao longo do tempo a ciência médica se caracterizou como a ciência que ditaria o modo e a maneira correta e saudável de se colocar no mundo ${ }^{4}$. Isto leva pais e professores a buscarem fora de seus domínios a resolução para seus problemas, apoiando-se na palavra final do especialista.

Com efeito, é bastante presente no discurso dos pais e responsáveis o fato de que as dificuldades surgiram na escola e, de certa forma, após o apontamento do problema, todos buscaram ajuda e seguiram as recomendações oferecidas pelos especialistas consultados. Tal fato parece estar relacionado ao processo de desresponsabilização dos pais e responsáveis diante dos sofrimentos e problemas enfrentados pelos filhos, o que acarreta a busca pelo saber do especialista por considerarem que o problema apresentado extrapolou a capacidade delegada à sua função parental ${ }^{3}$. 
Graças à busca por soluções milagrosas que possam sanar as dificuldades da vida é que inúmeras crianças são medicalizadas nas instituições de educação e, posteriormente, medicadas. Professores depositam essa incumbência na ciência médica, mas o problema, na maioria das vezes, tem outro caráter. A educação sofre influência de déficits não orgânicos, mas políticos, econômicos e sociais, como o baixo incentivo, salas lotadas, desvalorização da atuação profissional, além de cursos despreparados para formação de profissionais qualificados, entre inúmeros outros.

Percebe-se que as dificuldades apresentadas são compreendidas e localizadas unicamente no indivíduo, ou seja, na criança. Com efeito, considera-se que a forma de se compreenderem as pretensas dificuldades dos alunos está imersa na lógica medicalizante que tem como ferramenta a utilização de tecnologias e saberes para o controle do comportamento das crianças, o que reduz toda a constituição subjetiva, composta pelas relações familiares, escolares e sociais a apenas um diagnóstico e, portanto, a uma doença que justificaria falhas, dificuldades e sofrimentos.

\section{Colaboradores}

Os autores participaram, igualmente, de todas as etapas de elaboração do artigo.

\section{Referências}

1. Foucault M. Crise da medicina ou crise da antimedicina. Rev Verve. 2010; 1(18):167-194.

2. Iriart C, Rios LI. Biomedicalización e infancia: trastorno de déficit de atención e hiperactividad. Interface (Botucatu). 2012; 16(43):1011-23.

3. Vorcaro A. O efeito bumerangue da classificação psicopatológica da infância. In: Jerusalinsky A, Fendrik S, organizadores. O livro negro da psicopatologia contemporânea. $2 a$ ed. São Paulo: Via Lettera; 2011. p. 219-29.

4. Foucault M. O nascimento da Medicina Social. In: Foucault M. Microfísica do poder. Rio de Janeiro: Graal; 1979. p. 79-98.

5. Foucault M. O poder psiquiátrico: curso no Collège de France (1973-1974). São Paulo: Martins Fontes; 2006.

6. Illich I. A expropriação da saúde. Nêmesis da medicina. 3a ed. Rio de Janeiro: Nova Fronteira; 1975.

7. Martins AL. A psiquiatrização da vida na sociedade de controle. In: Carvalho SR, Barros $M E$, Ferigato $S$, organizadores. Conexões: saúde coletiva e políticas da subjetividade. São Paulo: Hucitec; 2009. p. 119-40.

8. Moysés MAA, Collares CAL. Dislexia e TDHA: uma análise a partir da ciência médica. In: Conselho Regional de Psicologia, Grupo Interinstitucional Queixa Escolar, organizadores. Medicalização de crianças e adolescentes: conflitos silenciados pela redução de questões sociais a doenças de indivíduos. São Paulo: Casa do Psicólogo; 2010. p. 71-110. 
9. Caliman LV. O TDAH: entre as funções, disfunções e otimização da atenção. Psicol Estud. 2008; 13(3):559-66.

10. Caliman LV, Domitrovic N. Uma análise da dispensa pública do metilfenidato no Brasil: o caso do Espírito Santo. Physis. 2013; 23(3):879-902.

11. Foucault M. Vigiar e punir: nascimento da prisão. 35a ed. Petrópolis: Vozes; 2008.

12. Deleuze G. Post-scriptum sobre as sociedades de controle. In: Deleuze G.

Conversações. Rio de Janeiro: Ed. 34; 1992. p. 219-26.

13. Machado AM. Plantão institucional: um dispositivo criador. In: Machado AA, Fernandes $A M D$, Rocha $M L$, organizadores. Novos possíveis no encontro da psicologia com a educação. São Paulo: Casa do Psicólogo; 2007. p. 117-45.

14. Costa JSF. História da psiquiatria no Brasil: um corte ideológico. 5 a ed. Rio de Janeiro: Garamond; 2007.

15. Patto MHS. A produção do fracasso escolar: história de submissão e rebeldia. 2a ed. São Paulo: Casa do Psicólogo; 2000.

16. Foucault M. A verdade e as formas jurídicas. 2a ed. Rio de Janeiro: Nau; 1999.

17. Prado Filho K, Trisotto S. A Psicologia como disciplina da norma nos escritos de $M$. Foucault. Rev Aulas Dossiê Foucault. 2007; 1(3):1-14.

18. Caliman LV. A biologia moral da atenção: a constituição do sujeito desatento [tese]. Rio de Janeiro (RJ): Programa de Pós-Graduação em Saúde Coletiva, Instituto de Medicina Social, Universidade do Estado do Rio de Janeiro; 2006.

19. Turato ER. Tratado da metodologia da pesquisa clínico-qualitativa. 2a ed. Rio de Janeiro: Vozes; 2003.

20. Moysés MAA. A institucionalização invisível: crianças que não aprendem na escola. São Paulo: Fapesp; 2001.

21. Mantilla MJ, Alonso JP. Transmisión del diagnóstico en psiquiatría y adscripción de identidades: perspectivas de los profesionales. Interface (Botucatu). 2015; 19(52):21-32.

22. Collares $C L$, Moysés $M A$, Ribeiro $M F$, organizadores. Novas capturas, antigos diagnósticos na era dos transtornos. Campinas: Mercado de Letras; 2013. 
Cruz MGA, Okamoto MY, Ferrazza DA. El caso del Transtorno do Déficit de Atención e Hiperactividad (TDAH) y la medicalización de la educación: un análisis a partir de la narración de padres y profesores. Interface (Botucatu). 2016; 20(58):703-14.

Las dificultades de comportamiento en la infancia han sido blanco de inúmeras discusiones en el área médica y educacional, sobre todo en los últimos años. Con esto, dos fenómenos interrelacionados sobresalen: la medicalización y la patologización de la infancia. La medicina y la psiquiatría son saberes productores de estos procesos al crear y recrear categorías diagnósticas que justifiquen inúmeros problemas de la red de relaciones complejas que caracterizan el ambiente escolar. Desde esta perspectiva, pretendemos traer el relato de padres y profesores de una escuela pública del interior de São Paulo sobre alumnos, con edad entre siete y 11 años, diagnosticados con Transtorno do Déficit de Atención e Hiperactividad (TDAH) y relacionarlo con las discusiones acerca del proceso de medicalización en la actualidad. Se considera que los niños que presentan dificultades de aprendizaje o comportamiento son categorizados como un cuerpo biológico a-histórico desprovisto de vida social y afectiva.

Palabras clave: TDAH. Medicalización. Infancia. Padres. Profesores.

Recebido em 09/10/15. Aprovado em 22/01/16 